\title{
钉(II)光活化化疗试剂研究进展
}

\author{
周前雄* 王雪松* \\ (中国科学院理化技术研究所光化学转换与功能材料重点实验室 北京 100190)
}

\begin{abstract}
摘要 许多钌(II)配合物在水溶液中可以发生光诱导配体解离, 形成的水合物能够与 DNA 共价结合. Ru(II)配合物的这 一特性近年来在抗癌药物研发领域被利用来发展新型光活化化疗试剂. 通过合理选择配体和调控配位构型, 光活化化 疗试剂可以实现抗癌活性物种在肿瘤组织的高选择性且计量可控的释放, 有希望在提高药物疗效的同时降低其毒副作 用. 本文对近年来钉(II)光活化化疗试剂的研究进展做了全面的综述, 并展望了该领域的未来发展方向.
\end{abstract}

关键词 化疗; 光活化; 钌(II)配合物; 配体解离

\section{Advances in Ru(II)-based Photoactivated Chemotherapy Agents}

\author{
Zhou, Qianxiong* Wang, Xuesong* \\ (Key Laboratory of Photochemical Conversion and Optoelectronic Materials, Technical Institute of Physics and Chemistry, \\ Chinese Academy of Sciences, Beijing 100190)
}

\begin{abstract}
Many Ru(II) complexes can undergo photoinduced ligand dissociation in aqueous solutions, and the formed aqua $\mathrm{Ru}(\mathrm{II})$ species may bind to DNA covalently. This property has been applied to develop novel photoactivated chemotherapy (PACT) agents for cancer treatment in recent years. By finely tuning ligand structures and coordination configurations, PACT may realize highly selective and on-demand release of active species in cancer tissues, leading to an improved efficacy and diminished side effects. In this review, the progress in $\mathrm{Ru}(\mathrm{II})$-based PACT agents was fully discussed and a perspective for their future development was included.
\end{abstract}

Keywords chemical therapy; photoactivation; Ru(II) complexes; ligand dissociation

\section{1 引言}

新型癌症化疗药物研发多年来一直是医药及其相 关领域的研究重点, 其中, 过渡金属配合物类化疗药物 研究始终是热点之一 ${ }^{[1 \sim 7]}$, 这显然得益于顺铂 [cis- $\mathrm{Pt}\left(\mathrm{NH}_{3}\right)_{2} \mathrm{Cl}_{2}$ ]长期而广泛的临床应用. 20 世纪 60 年 代 Rosenberg 及其合作者 ${ }^{[8,9]}$ 的意外发现揭示了顺铂的抗 肿瘤活性，随后世界范围的深入研发推动了顺铂及其 5 种类似物成功用于癌症的临床治疗 (图 1) ${ }^{[10]}$. 它们的作 用靶点被普遍认为是细胞核内的遗传物质 $\mathrm{DNA}^{[11]}$. 以 顺铂为例, 细胞内部较低的 $\mathrm{Cl}^{-}$离子浓度促进了两个 $\mathrm{Cl}$ 配体的依次解离, 生成的水合物 $\left[c i s-\mathrm{Pt}\left(\mathrm{NH}_{3}\right)_{2}\left(\mathrm{H}_{2} \mathrm{O}\right)_{2}\right]$ 可 与 DNA 的嘌呤(尤其是鸟嘌呤)碱基共价结合, 导致 DNA 链内交联和链间交联, 从而阻断 DNA 的转录与复 制, 诱导癌细胞死亡. 由于水解速度较快, 顺铂在到达 DNA 靶点之前就与细胞内甚至是血液中的生物活性分 子结合, 这不仅降低了疗效, 还导致众多毒副作用. 基 于二羧基离去配体的 Pt 药物(如卡铂和奥沙利铂)水解速 率得到有效调控, 毒副作用较顺铂有所降低 ${ }^{[12]}$. 基于这 一药物构效关系, 近年来 $\mathrm{Pt}(\mathrm{IV})$ 前药的研发备受关注, 图 2 所示的几种该类型配合物已进入临床试验阶段 ${ }^{[12]}$.
与顺铂及其类似物的平面四方配位构型不同，Pt(IV)配 合物为八面体六配位构型, 具有较高的稳定性, 在细胞 内被还原后释放两个轴向配体, 产生类似顺铂的抗癌活 性物种. 轴向配体不仅可以用来调控前药的亲水疏水平 衡，还可以修饰对癌细胞具有靶向性的基团 ${ }^{[13]}$. 在众多 已报道的 $\mathrm{Pt}(\mathrm{IV})$ 配合物中, 含叠氮配位基团的配合物尤 为独特(图 3) ${ }^{[14 \sim 16]}$. 光照这些含叠氮配体的 $\mathrm{Pt}(\mathrm{IV})$ 配合 物可引起配体解离以及 $\operatorname{Pt}(\mathrm{II})$ 抗癌活性物种的生成. 由 于可以在时间和空间上对光照进行精确操纵, 从而使抗 癌活性物种在肿瘤组织的高选择性释放成为可能. 该类 前药常被称为光活化化疗 (photoactivated chemotherapy, PACT)药物 ${ }^{[17,18]}$.

其实, 光活化抗癌药物已得到临床应用, 即所谓的 光动力疗法(photodynamic therapy, PDT) ${ }^{[19]}$, 它是利用光 敏剂、光和氧气三者相互作用产生的活性氧物种(主要 为单重态氧, ${ }^{1} \mathrm{O}_{2}$ ) 有效灭活癌细胞. 一个光敏剂可以产 生众多的单重态氧分子, 这种催化特性赋予光动力疗法 高的活性. 但遗憾的是, 许多实体肿瘤细胞由于快速的 增殖以及不足的血供状态而处于乏氧环境 ${ }^{[20,21]}$, 致使光 动力疗法对该类肿瘤细胞活性低下. 与光动力疗法

\footnotetext{
* E-mail: zhouqianxiong@mail.ipc.ac.cn, xswang@mail.ipc.ac.cn Received September 5, 2016; published October 9, 2016. Project supported by the National Natural Science Foundation of China (Grant Nos. 21273259, 21571181). 项目受国家自然科学基金(Grant Nos. 21273259, 21571181)资助.
} 


$$
\begin{aligned}
& \mathrm{H}_{3} \mathrm{~N} \\
& \mathrm{H}_{3} \mathrm{~N}-\mathrm{Pt}
\end{aligned}-\mathrm{Cl}
$$<smiles>O=C1OC2(NC3CCCCC3N2)OC1=O</smiles>

oxaliplatin<smiles>N[P+](N)(N)OC(=O)C1(C(=O)OCCCCCO)CCC1</smiles><smiles>N[PH]1(N)OCC(=O)O1</smiles>

nedaplatin<smiles>CC(C)C1OC2CN[PH]3(NCC2O1)OC(=O)CC(=O)O3</smiles>
heptaplatin<smiles>CNCC1CCC1CN[PH]1(NC)OC(=O)CC(C)O1</smiles>

lobaplatin

图 1 临床应用的 $\mathrm{Pt}(\mathrm{II})$ 类抗癌药物

Figure $1 \mathrm{Pt}(\mathrm{II})$ anticancer drugs that have been clinically approved

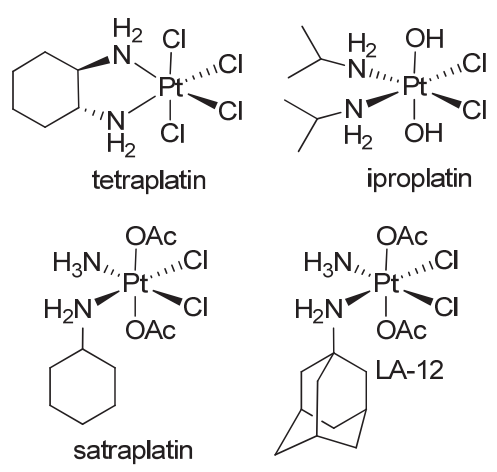

图 2 临床实验的 $\mathrm{Pt}(\mathrm{IV})$ 类抗癌试剂

Figure $2 \mathrm{Pt}(\mathrm{IV})$ anticancer agents that have been clinically tested

$$
\text { 等, }
$$

trans, trans,trans$\left[\mathrm{Pt}\left(\mathrm{N}_{3}\right)_{2}(\mathrm{OH})_{2}\left(\mathrm{NH}_{3}\right)(\mathrm{py})\right]$<smiles></smiles>

cis,trans-[Pt $\left.\left(\mathrm{N}_{3}\right)_{2}(\mathrm{Sub})_{2}(t-\mathrm{Bubpy})\right]$

图 3 含叠氮配体的 $\mathrm{Pt}(\mathrm{IV})$ 光活化抗癌试剂

Figure $3 \mathrm{Pt}(\mathrm{IV})$ photoactivated anticancer agents that contain $\mathrm{N}_{3}$ ligands

不同, 光活化化疗药物对细胞内的氧气含量没有依赖 性，可对乏氧癌细胞实施有效灭活，成为近年来光活化 抗癌药物研发的新方向.

除了 Pt 配合物, 许多过渡金属配合物也具备光诱

导配体解离介导的 DNA 共价结合能力，成为光活化化 疗药物研发新方向, 其中以钓配合物的研究最为广泛深 $\lambda^{[22]}$. 这一方面是由于钓配合物具有丰富的光物理、光 化学和电化学活性, 另一方面也是受到两个已进入临床 实验阶段的 Ru(III)药物 NAMI-A 和 KP1019(图 4)的鼓 舞 ${ }^{[23]}$. 与关注 $\mathrm{Ru}(\mathrm{III})$ 配合物化疗活性不同，对于 $\mathrm{Ru}(\mathrm{II})$ 配合物，人们更关注其光活化化疗活性，相关工作从 2010 年后发展尤为迅速，但迄今还缺乏对其专门和全 面的综述，本文无疑成为人们了解该领域最新进展的有 益参考.

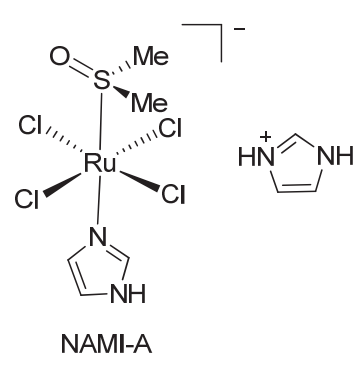

图 4 临床实验的 $\mathrm{Ru}(\mathrm{III})$ 类抗癌试剂

Figure $4 \mathrm{Ru}(\mathrm{III})$ anticancer agents that have been clinically tested

$\mathrm{Ru}(\mathrm{II})$ 配合物的最低能量吸收带往往具有 MLCT (metal-to-ligand charge transfer) 属性，被处于该谱带的光 线激发后, $\mathrm{Ru}(\mathrm{II})$ 配合物首先到达 ${ }^{1} \mathrm{MLCT}$ 态，再经超快 系间窝越(intersystem crossing)到达 ${ }^{3} \mathrm{MLCT}$ 态(图 5). ${ }^{3} \mathrm{MLCT}$ 态既可以通过无辐射失活或发光形式回到基态， 也可以与其它分子发生分子间相互作用, 呈现出光动力 活性. 例如, ${ }^{3} \mathrm{MLCT}$ 态可将能量传递给氧气生成单重态 氧, 进而断裂 DNA 和灭活细胞 ${ }^{24 \sim 29]}$, 即所谓的光动力 II 型机制, 或能量传递机制. 当 ${ }^{3} \mathrm{MLCT}$ 态氧化能力足够 强时, 也可以直接氧化生物分子 (如 $\mathrm{DNA}^{[30 \sim 33]}$ ), 即所谓 的光动力 I 型机制, 或电子转移机制. 本文重点介绍的 则是另一光化学过程: 激发态分子从 ${ }^{3} \mathrm{MLCT}$ 态借助热 活化到达 ${ }^{3} \mathrm{MC}$ 态(metal-centered state 或 ligand-field state), 该激发态具有金属-配体反键轨道特征，可导致 配体解离，同时产生对 DNA 具有共价结合能力的 Ru 活 性物种, 表现出光活化化疗潜力. 钓配合物的光诱导配 体解离特性近年来还被用于生物活性组分、成像试剂乃 至各类药物的靶向输送以及生物活性物种或光电功能 材料功能基团的保护和光活化，这方面的工作不在本文 给予介绍, 感兴趣的读者可参阅相关文献 ${ }^{[34 \sim 42]}$.

\section{2 钉多吡啶配合物单齿配体光解离}

$\mathrm{Ru}(\mathrm{II})$ 配合物的配体光解离现象早在 20 世纪 70 年 代就得到深入研究 ${ }^{[43 ~ 46]}$, 但有意识地利用该性质发展 DNA 光交联试剂及光活化抗癌药物的工作还是始于 Turro 团队 ${ }^{[47]} 2004$ 年的一篇报道. 他们考察了 cis- 


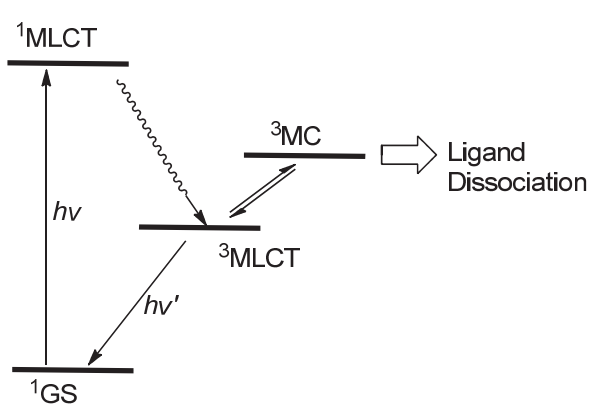

图 5 配体光解离 $\mathrm{Ru}(\mathrm{II})$ 配合物的 Jablonski 能级示意图

Figure 5 Jablonski diagram of a $\mathrm{Ru}(\mathrm{II})$ complex with photolabile ligands

$\left[\mathrm{Ru}(\mathrm{bpy})_{2}\left(\mathrm{NH}_{3}\right)_{2}\right]^{2+}$ (配合物 $\mathbf{1}$, 图 6), 水溶液中光照可引 起两个 $\mathrm{NH}_{3}$ 单齿配体依次解离, 即吸收一个光子只能导 致一个单齿配体解离, 最终生成二水合物 $c i s-\left[\mathrm{Ru}(\mathrm{bpy})_{2}\left(\mathrm{H}_{2} \mathrm{O}\right)_{2}\right]^{2+}$. 配体光解离呈现出波长依赖性, $350 \mathrm{~nm}$ 和 $400 \mathrm{~nm}$ 光照下, 二水合物生成效率分别为 0.024 和 0.018. 在 9-甲基(乙基)-鸟嘌呤以及单链和双链 DNA 存在时, 观察到配合物与碱基的共价结合, 这种结 合作用减缓了线型质粒 DNA 的电泳迁移速率.

单齿配体的光解离效率与其配位能力紧密相关. 与

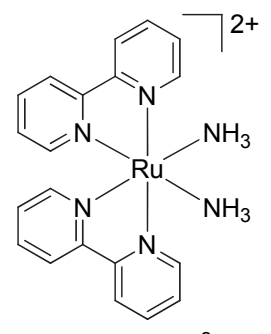

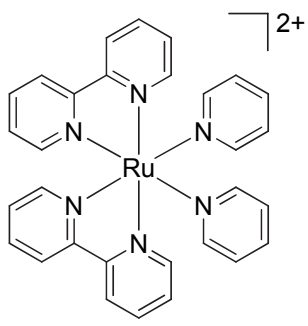

$\left[\mathrm{Ru}(\mathrm{bpy})_{2}(\mathrm{py})_{2}\right]^{2+}(\mathbf{2})$
1 相比, cis- $\left[\mathrm{Ru}(\mathrm{bpy})_{2}(\mathrm{py})_{2}\right]^{2+}$ (2)在乙腈溶液中吡啶配体 与 $\mathrm{Cl}^{-}$的光诱导配体交换效率仅为 $0.0059^{[48]}$, 而 cis- $\left[\mathrm{Ru}(\mathrm{bpy})_{2}\left(\mathrm{CH}_{3} \mathrm{CN}\right)_{2}\right]^{2+}(\mathbf{3})$ 的水溶液光照形成二水合 物 $c i s-\left[\mathrm{Ru}(\mathrm{bpy})_{2}\left(\mathrm{H}_{2} \mathrm{O}\right)_{2}\right]^{2+}$ 的量子效率则高达 0.38 (350 $\mathrm{nm})$ 和 $0.22(450 \mathrm{~nm})^{[49]}$.

单齿配体的光解离效率还与 $\mathrm{Ru}(\mathrm{II})$ 配合物八面体配 位构型的扭曲程度相关. 当配体含有位阻基团或配体的 刚性结构阻碍其与 $\mathrm{Ru}$ 中心以最佳角度螯合时, 将得到 扭曲的八面体配位构型，这会降低配位场裂分能和 ${ }^{3} \mathrm{MC}$ 态能级，导致 ${ }^{3} \mathrm{MC}$ 与 ${ }^{3} \mathrm{MLCT}$ 能级差减小，致使 ${ }^{3} \mathrm{MC}$ 态 更易通过热活化经由 ${ }^{3} \mathrm{MLCT}$ 态布居, 宏观表现就是单 齿配体光解离效率得到提升. [Ru(TPA) $\left(\mathrm{CH}_{3} \mathrm{CN}\right)_{2}$ ]系列 配合物 $(4 \sim 7)$ 的光化学行为非常好地体现出了位阻效 应 ${ }^{[50]}$. 在 $\mathrm{CH}_{2} \mathrm{Cl}_{2}$ 溶液中 4 的单齿 $\mathrm{CH}_{3} \mathrm{CN}$ 配体与溶液中 的 $\mathrm{Cl}^{-}$离子的光诱导交换效率为 $0.016(400 \mathrm{~nm})$, 而同样 条件下 5 的效率则为 0.041 . 由于 6 和 7 中位阻效应过大, 两个配合物即使避光条件下也能发生单齿 $\mathrm{CH}_{3} \mathrm{CN}$ 配体 与 $\mathrm{Cl}^{-}$离子的交换. $4 \sim 7$ 在水溶液中 $\mathrm{CH}_{3} \mathrm{CN}$ 配体与水分 子的光诱导配体交换也遵循相似的位阻效应.
$\left[\mathrm{Ru}(\mathrm{bpy})_{2}\left(\mathrm{NH}_{3}\right)_{2}\right]^{2+}$ (1)

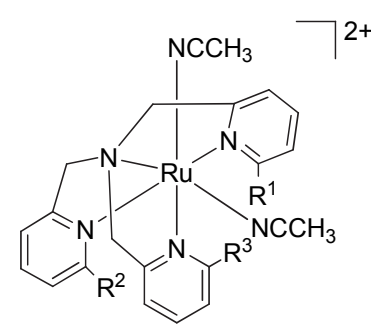

$\left[\mathrm{Ru}(\mathrm{TPA})\left(\mathrm{CH}_{3} \mathrm{CN}\right)_{2}\right]^{2+} \mathrm{R}^{1}=\mathrm{R}^{2}=\mathrm{R}^{3}=\mathrm{H}(4)$ $\left[\mathrm{Ru}(\mathrm{MeTPA})\left(\mathrm{CH}_{3} \mathrm{CN}\right)_{2}\right]^{2+} \mathrm{R}^{1}=\mathrm{Me}, \mathrm{R}^{2}=\mathrm{R}^{3}=\mathrm{H}(\mathbf{5})$ $\left[\mathrm{Ru}\left(\mathrm{Me}_{2} \mathrm{TPA}\right)\left(\mathrm{CH}_{3} \mathrm{CN}\right)_{2}\right]^{2+} \mathrm{R}^{1}=\mathrm{R}^{2}=\mathrm{Me}, \mathrm{R}^{3}=\mathrm{H}(\mathbf{6})$ $\left[\mathrm{Ru}\left(\mathrm{Me}_{3} \mathrm{TPA}\right)\left(\mathrm{CH}_{3} \mathrm{CN}\right)_{2}\right]^{2+} \mathrm{R}^{1}=\mathrm{R}^{2}=\mathrm{R}^{3}=\mathrm{Me}(\mathbf{7})$

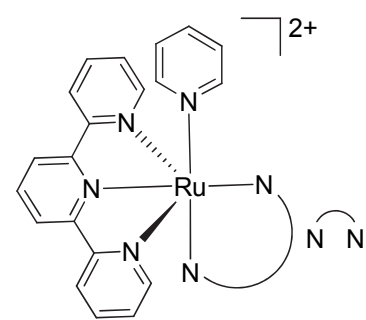

$[\mathrm{Ru}(\mathrm{tpy})(\mathrm{NN})(\mathrm{py})]^{2+}$<smiles></smiles>

$\left[\mathrm{Ru}(\mathrm{bpy})_{2}\left(\mathrm{CH}_{3} \mathrm{CN}\right)_{2}\right]^{2+}(3)$

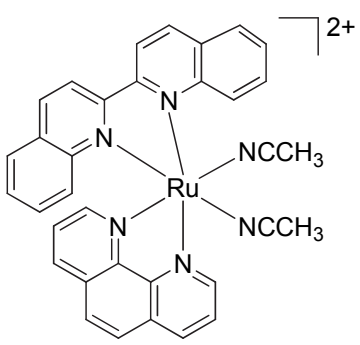

$\left[\mathrm{Ru}(\mathrm{biq})(\text { phen })\left(\mathrm{CH}_{3} \mathrm{CN}\right)_{2}\right]^{2+}$ (11)

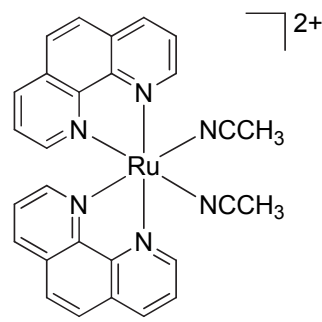

$\left[\mathrm{Ru}(\text { phen })_{2}\left(\mathrm{CH}_{3} \mathrm{CN}\right)_{2}\right]^{2+}(\mathbf{1 2})$<smiles>c1ccc(-c2ccccn2)nc1</smiles><smiles>Cc1cccc(-c2cccc(C)n2)n1</smiles>

8

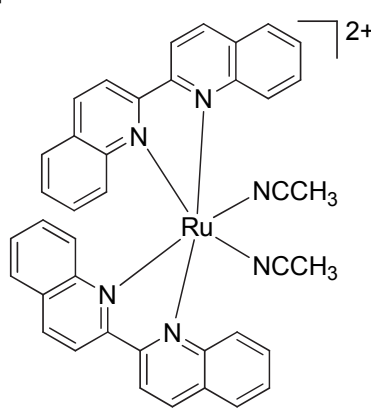

$\left[\mathrm{Ru}(\mathrm{biq})_{2}\left(\mathrm{CH}_{3} \mathrm{CN}\right)_{2}\right]^{2+}(\mathbf{1 3})$

图 6 光诱导单齿配体解离 $\mathrm{Ru}(\mathrm{II})$ 多吡啶配合物

Figure 6 Polypyridyl Ru(II) complexes with photolabile monodentate ligands 
位阻效应在配合物 $\mathbf{8} \sim \mathbf{1 0}$ 中也得到体现 ${ }^{[51]}$. 光照 9 和 10 的乙腈溶液得到单齿配体交换产物 $\left[\mathrm{Ru}(\mathrm{tpy})(\mathrm{NN})\left(\mathrm{NCCH}_{3}\right)\right]^{2+}\left(\mathrm{NN}=\mathrm{Me}_{2} \mathrm{bpy}, \mathrm{biq}\right), 500 \mathrm{~nm}$ 光 照测得量子效率分别为 0.16 (9)和 0.033 (10), 同样条件 下 8 的单齿配体吡啶与乙腈的交换效率小于 0.0001 .

上述配合物中的两个单齿配体的解离都是分步进 行的, 但最终都能得到完全解离对应的产物. 配合物 $c i s-\left[\mathrm{Ru}(\mathrm{biq})(\mathrm{phen})\left(\mathrm{CH}_{3} \mathrm{CN}\right)_{2}\right]^{2+}$ (11) 的单齿配体解离行为 则非常独特 ${ }^{[52]}$. 当长波长光激发时 $(>550 \mathrm{~nm})$, 只有一 个乙腈配体与溶剂分子发生交换, 而短波光激发时 $(>420 \mathrm{~nm})$, 两个乙腈配体均能与溶剂分子交换. 结构 类似配合物 12 和 13 则在两种光照条件下两个乙腈配体 均能与溶剂分子交换. 理论计算对实验现象给出了一定 的解释. 11 的配体光解离可能经由所谓的 “dissociative” 机制, 即配体先离去, 生成五配位中间体. 计算表明能 量最低的五配位中间体的配位空位与 phen 成 trans 构型, 意味着与 phen 成 trans 构型的乙腈配体优先离去. 此外, 假定吡啶配体进攻五配位中间体, 理论计算表明产物中 吡啶配体与 phen 成 trans 构型时能量最低, 同样支持与 phen 成 trans 构型的乙腈配体优先离去.

\section{3 钉多吡啶配合物双齿配体光解离}

与单齿配体相比较, 双齿配体的光解离要困难得 多. 虽然 $c i s-\left[\mathrm{Ru}(\mathrm{bpy})_{2}\left(\mathrm{NH}_{3}\right)_{2}\right]^{2+}(\mathbf{1})$ 的两个 $\mathrm{NH}_{3}$ 配体具有 较高的光解离效率, 当把两个 $\mathrm{NH}_{3}$ 通过亚乙基相连后, 配合物 $\left[\mathrm{Ru}(\mathrm{bpy})_{2}(\mathrm{en})\right]^{2+}\left(\mathbf{1 4}\right.$, 图 7)中 en 双齿配体与 $\mathrm{Cl}^{-}$ 离子的交换量子效率仅为 $0.002^{[53]}$. 配合物 15 与 14 相 似，配体交换量子效率为 0.003 .

提高双齿配体解离效率的一个有效策略是减弱配 位原子的配位能力. 例如, 与 14 和 15 比较, 配合物 16 和 17 中双硫醚配体的光解离量子效率有显著增加, 分 别为 0.019 和 $0.016^{[53]}$. 这两个配合物光照条件下能够有 效阻滞线型质粒 DNA 的凝胶电泳速率, 说明它们能与 DNA 发生共价结合作用, 展现出光活化化疗潜力.

提高双齿配体解离效率的另一有效策略就是利用 位阻效应. Glazer 团队 ${ }^{[54]}$ 设计合成了两个新型 $\mathrm{Ru}$ 配合物 18 和 19, 并对照研究了 $\left[R u(b p y)_{2}(\text { phen })\right]^{2+}(\mathbf{2 0})$. 通过两 个甲基基团的取代，位阻效应被成功引入到配合物 18 和 19 中. 光照这两个配合物, $\mathrm{Me}_{2} \mathrm{bpy}$ 配体和 $\mathrm{Me}_{2} \mathrm{dpq}$ 配 体有效解离, 生成的水合物能与质粒 DNA 共价结合,

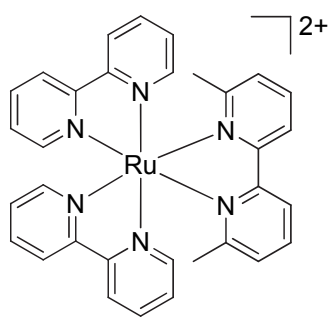

$\left[\mathrm{Ru}(\mathrm{bpy})_{2}\left(\mathrm{Me}_{2} \mathrm{bpy}\right)\right]^{2+}(\mathbf{1 8})$

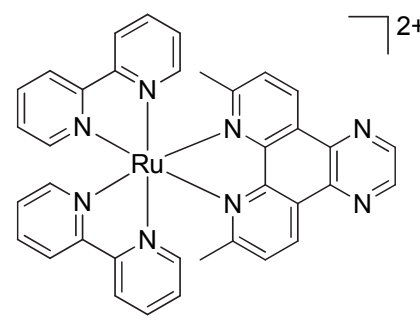

$\left[\mathrm{Ru}(\mathrm{bpy})_{2}\left(\mathrm{Me}_{2} \mathrm{dpq}\right)\right]^{2+}($ (19)

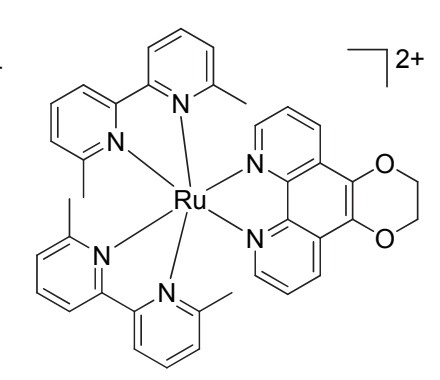

$\left[\mathrm{Ru}\left(\mathrm{Me}_{2} \text { phen }\right)_{2}(\mathrm{dop})\right]^{2+}(23)$

$(23)$

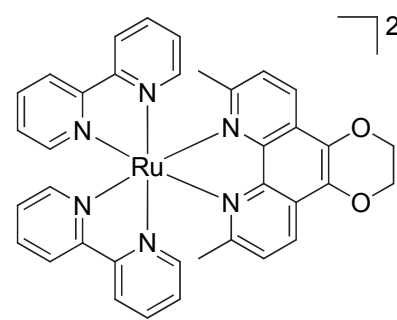

$\left[\mathrm{Ru}(\mathrm{bpy})_{2}\left(\mathrm{Me}_{2} \mathrm{dop}\right)\right]^{2+}(\mathbf{2 2})$

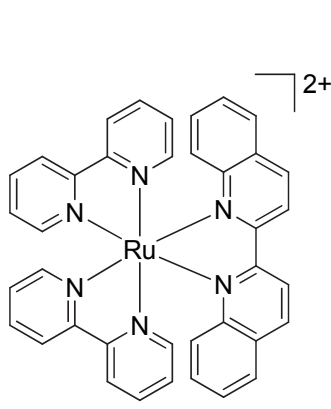

$\left[\mathrm{Ru}(\text { phen })_{2}(\mathrm{biq})\right]^{2+}(\mathbf{2 4})$

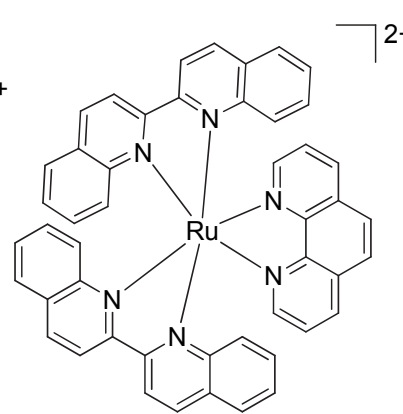

$\left[\mathrm{Ru}(\mathrm{biq})_{2}(\text { phen })\right]^{2+}(\mathbf{2 5})$

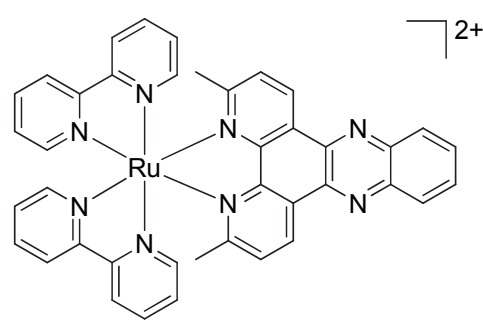

$\left[\mathrm{Ru}(\mathrm{bpy})_{2}\left(\mathrm{Me}_{2} \mathrm{dppz}\right)\right]^{2+}(\mathbf{2 6})$

图 7 光诱导双单齿配体解离 $\mathrm{Ru}(\mathrm{II})$ 多吡啶配合物

Figure 7 Polypyridyl Ru(II) complexes with a photolabile bidentate ligand 
显著减慢其凝胶电泳迁移速率. 配合物 20 光照下无配 体解离发生, 但可以通过能量传递作用产生单重态氧, 从而导致 DNA 断裂. 有趣的是, 19 可同时断裂 DNA 和 交联 DNA, 这与其光解离效率较 18 低 30 余倍相符合. 较慢的光解离速率赋予了 19 一定的稳定性, 有利于单 重态氧的产生. 值得一提的是, 18 和 19 对白血病细胞 HL60 和肺癌细胞 A549 呈现出优异的光活化灭活能力, 与其暗毒性相比，它们的光毒性提高了 100 余倍.

依据同样的理念, 一系列具有位阻效应的 $\mathrm{Ru}$ 配合 物得到深入研究. 与配体解离惰性的配合物 21 相比, 配 合物 22 和 23 光照后喹喔啉配体解离, 由于位阻效应更 大, 23 的配体解离速率明显快于 $\mathbf{2 2}^{[55]}$. 对于 HL60 癌细 胞, 23 的光毒性较其暗毒性提高了 1880 倍! 其光毒性比 顺铂的药物毒性也高了近 19 倍.

双喹啉配体(biq)不仅具有位阻效应, 其共轭结构还 有助于延长配合物的吸收波长. 与此预期相一致, 配合 物 24 和 25 的 MLCT 最大吸收波长分别为 $525 \mathrm{~nm}$ 和 550 $\mathrm{nm}$, 较配合物 20 红移了近 $100 \mathrm{~nm}^{[56]}$. 两个配合物光照 后均能释放双喹啉配体, 导致质粒 DNA 电泳速率变慢, 并在红光照射下对 HL-60 细胞呈现出光毒性. 最近, Glazer 团队 ${ }^{[57]}$ 还利用高分子交联组装体负载具有位阻 效应的 $\mathrm{Ru}$ 配合物, 研究了配合物负载效率以及活性组 分光释放效率与配合物的亲水亲脂特性、溶液离子强度 和 $\mathrm{pH}$ 的关系.

在已报道的基于位阻效应实现双齿配体光解离的 体系中, 配合物 $\left[\mathrm{Ru}(\mathrm{bpy})_{2}\left(\mathrm{Me}_{2} \mathrm{dppz}\right)\right]^{2+}(\mathbf{2 6})$ 的性质值得 关注. 基于 $d p p z$ 配体的钉配合物 $\left[R u(b p y)_{2}(d p p z)\right]^{2+}$ 具有 “DNA 光开关” 特性, 即在水溶液中不发光, 当与 DNA 发生嵌插作用后, 吩嗪环上 2 个 $\mathrm{N}$ 原子与水分子的氢键 作用被抑制, 配合物呈现出强发光 ${ }^{[58]}$. 与此相对应, 配 合物 26 在水溶液中具有良好的光稳定性, 虽然 $\mathrm{Me}_{2} \mathrm{dppz}$ 配体具有位阻效应, 光诱导解离速率却非常的慢; 当与 DNA 嵌插结合后, $\mathrm{Me}_{2} \mathrm{dppz}$ 配体光解离过程被开启, 导 致配合物与 DNA 发生共价结合 ${ }^{[59]}$. 随后, 同一团队深 入研究了配合物 26 的光诱导 $\mathrm{Me}_{2} \mathrm{dppz}$ 配体解离速率与 交换配体的种类、浓度以及环境温度间的依赖关系, 提 出配体光解离是经由所谓的 “associative” 机制, 即配合 物先与交换配体配位, 形成七配位中间体, 继而失去位 阻配体 $\mathrm{Me}_{2} \mathrm{dppz}^{[60]}$. 蛋白质特定的空间结构给形成七配 位中间体带来难度, 所以虽然 26 与蛋白质非共价结合 后处于低极性和非质子溶剂的环境中, 吩嗪环上 $\mathrm{N}$ 原子 与介质的氢键作用得到了有效抑制, 但光致配体解离效 率依然低下. 近期, 他们又在 $\mathrm{Me}_{2} \mathrm{dppz}$ 配体末端苯环上 引入一个溴原子, 所得配合物对四链 DNA 结构具有高 的选择性 ${ }^{[61]}$.

\section{4 与 “反铂” 相对应的 “反钓” 配合物}

虽然顺铂具有强的抗肿瘤活性, 但初期研究显示
“反铂” (trans-diaminedichloro platinum(II), 图 8)对肿瘤 细胞毫无影响，使得早期抗肿瘤 Pt 药物研发中将离去 配体的顺式结构作为一条铁律 ${ }^{[62,63]}$. 随着研究的深入, 人们发现当把 “反铂” 的一个 $\mathrm{NH}_{3}$ 配体改换成含 $\mathrm{N}$ 杂 环配体、亚胺醚类配体或脂肪胺配体时，相应配合物表 现出优异的抗肿瘤活性 ${ }^{[13]}$. 前述的 $\mathrm{Ru}$ 光活化化疗试剂 光照释放离去配体后, 两个配位活性位点均处于顺式构 型，那么如果处于反式构型，情况又会如何? 最近的两 篇报道对这个问题给予了回答.

Bonnet 团队 ${ }^{[64]}$ 设计合成了图 8 所示的配合物 27 和 28. 水溶液中 27 的轴向 $\mathrm{Cl}$ 配体在暗处就可以与 $\mathrm{H}_{2} \mathrm{O}$ 分 子发生配体交换, 光照后, 另一轴向配体则可进一步与 $\mathrm{H}_{2} \mathrm{O}$ 分子交换, 生成反式二水合物; 28 的两个轴向配体 则具有非常高的稳定性，只有在光照后，其中一个才发 生解离, 生成单水合物. 绿光(520 nm)照射下, 27 和 28 均表现出光活化化疗活性, 光毒性比暗毒性提高数倍到 二十余倍.

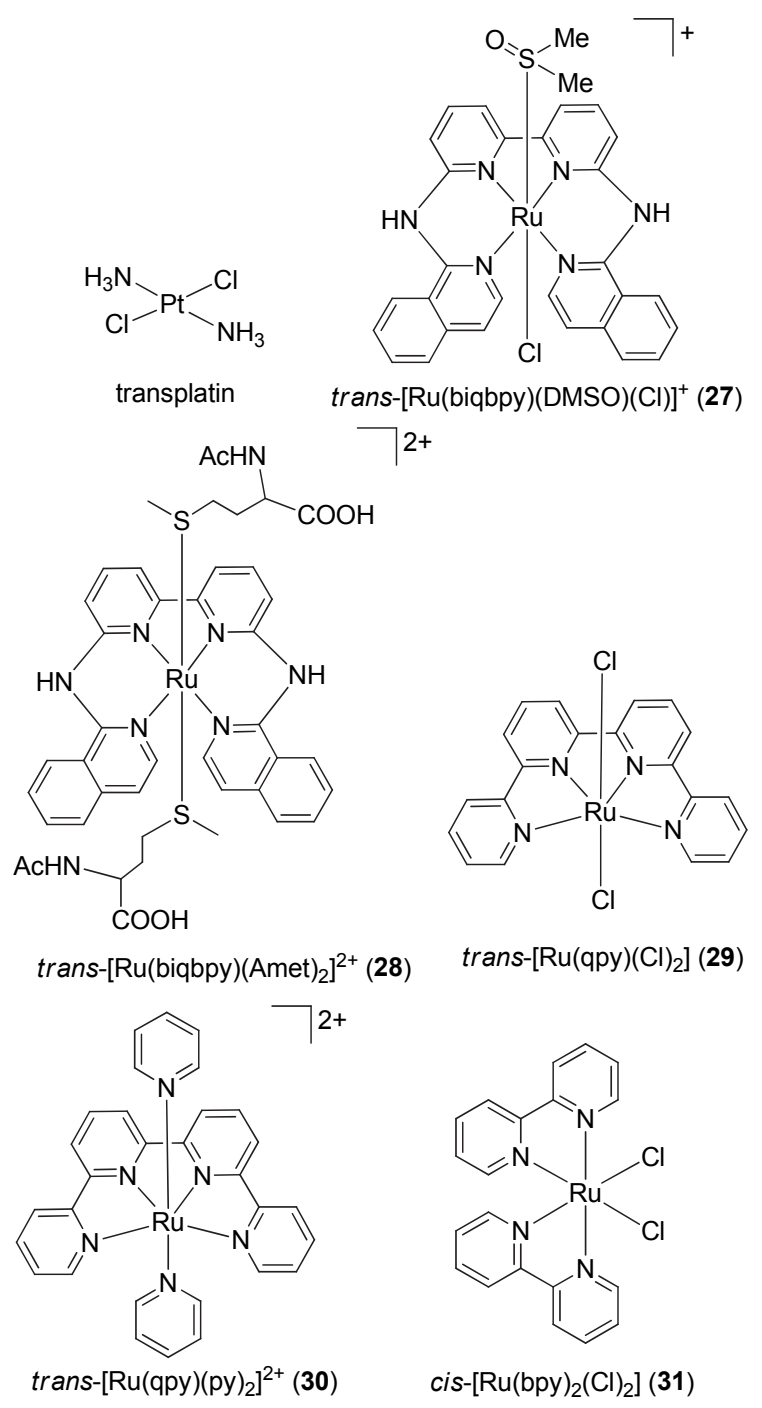

图 8 离去配体成反式构型的 $\mathrm{Ru}(\mathrm{II})$ 多吡啶配合物

Figure 8 Polypyridyl $\mathrm{Ru}(\mathrm{II})$ complexes with leaving ligands in trans-configuration 
与此同时, Glazer 团队 ${ }^{[65]}$ 研究了配合物 29 和 30 的 配体解离及细胞毒性, 并与配合物 $\mathbf{3 1}$ 和配合物 $\mathbf{2}$ 的性能 做了对照. 四个配合物中, 只有 29 和 31 中的单齿 $\mathrm{Cl}$ 配 体可以和溶剂分子发生配体交换反应. 细胞毒性实验显 示, 只有 29 对 HL-60 和 A549 细胞呈现明显的暗毒性, 其余三个配合物的细胞毒性微弱. 作者认为顺式结构的 31 由于两个 $\mathrm{Cl}$ 配体的解离速率过快, 导致其与细胞培 养液中的组分(如蛋白等)共价结合, 阻碍其进入肿瘤细 胞内部，抑制了它的细胞毒性. 细胞摄取实验一定程度 上支持了这一解释, 反式结构的 29 的细胞摄取量比 31 高出 49 倍. 遗憾的是作者在本工作中没有研究四个配 合物的光毒性. 这两个团队的研究结果为基于钉配合物 的光活化化疗试剂的研发提供了新思路.

\section{5 光活化波长延长策略}

与光动力疗法一样, 光活化化学疗法中光活化波长 依然是关系到治疗效果的重要因素. 理想的光疗窗口介 于 $650 \sim 850 \mathrm{~nm}$ 之间 ${ }^{[66]}$, 而上述钓配合物的 MLCT 吸收 带主要处于蓝光波段 $(<500 \mathrm{~nm})$, 如何拓展这类配合物 的光活化波长成为需要解决的重要问题之一.

如上所述, 双喹啉配体(biq)的大共轭结构为配合物 24 和 25 光活化波长的延长起到了促进作用. 大共轭体 系一方面降低了双喹啉配体的 $\pi$ 轨道能量, 从而降低了 ${ }^{1} \operatorname{MLCT}\left[\mathrm{t}_{2 \mathrm{~g}}(\mathrm{Ru})\right.$ to $\pi^{*}$ (biq)] 跃迁能, 一方面造成了空间 位阻, 通过配位场扭曲降低 ${ }^{3} \mathrm{MC}$ 态能量, 从而确保了低
光子能量激发 MLCT 带依然有高效的经由 ${ }^{3} \mathrm{MC}$ 态的配 体解离.

环金属化配体(如 2-苯基吡啶，phpy)与 $\mathrm{Ru}$ 配位后， 其碳负离子强的 $\sigma$ 给电子能力可以显著提升 $\mathrm{Ru}$ 的 $\mathrm{t}_{2 \mathrm{~g}}$ 轨 道能量, 从而大幅度延长配合物 MLCT 态吸收波长. 利 用这一性质, Turro 小组 ${ }^{[67]}$ 设计合成了图 9 所示的配合物 cis- $\left[\mathrm{Ru}(\mathrm{phpy})(\mathrm{phen})\left(\mathrm{CH}_{3} \mathrm{CN}\right)_{2}\right]^{+}(\mathbf{3 2})$, 其 $\mathrm{Ru}$ 到 phen 配体 的 MLCT 态吸收峰位于 $490 \mathrm{~nm}$, 尾带延长至光疗窗口, 激发该吸收带单齿乙腈配体与溶液中 $\mathrm{Cl}^{-}$的配体交换量 子效率高达 0.25 . 与前述光诱导配体解离的波长依赖性 不同，当用 $450 \mathrm{~nm}$ 的光激发 32 时，其配体交换效率降 低为 0.08 . 作者认为该波长激发引起的主要是 $\mathrm{Ru}$ 到 phpy 配体的 MLCT 跃迁, 由于该吸收带所含 phpy 配体 自身的 $\pi \pi$ *跃迁成分过多, 致使配体解离效率不升反降.

Turro 小组 ${ }^{[68]}$ 进一步将 phpy 配体与 biq 配体相结合, 设计合成了配合物 $\left[\mathrm{Ru}(\mathrm{biq})_{2}(\mathrm{phpy})\right]^{+}(\mathbf{3 3})$. 虽然 33 的吸 收波长比 24 和 25 红移约 $100 \mathrm{~nm}$, 但出乎预料的是光照 不能引起配体的解离. 理论计算表明环金属配体强的 $\sigma$ 给电子能力增强了配位场裂分能, ${ }^{3} \mathrm{MC}$ 态能级升高, 致 使 ${ }^{3} \mathrm{MC}$ 与 ${ }^{3} \mathrm{MLCT}$ 能级差增加, 配合物难于从 ${ }^{3} \mathrm{MLCT}$ 态经热活化布居到 ${ }^{3} \mathrm{MC}$ 态.

巢晖和计亮年团队 ${ }^{[69]}$ 考察了基于三联吡啶配体的 三个钓配合物 $(34 \sim 36)$ 的光诱导配体解离性能, 配合物 36 的 MLCT 最大吸收峰位于 $510 \mathrm{~nm}$ 左右. 三个配合物 在缓冲溶液中光照均能释放单齿 $\mathrm{Cl}^{-}$配体. 作者还研究

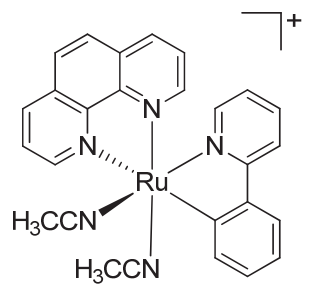

$\left[\mathrm{Ru}(\text { phpy })(\text { phen })\left(\mathrm{CH}_{3} \mathrm{CN}\right)_{2}\right]^{+}(\mathbf{3 2})$

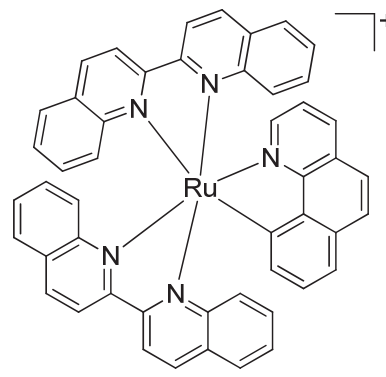

$\left[\operatorname{Ru}(\text { biq })_{2}(\text { phpy })\right]^{+}(\mathbf{3 3})$

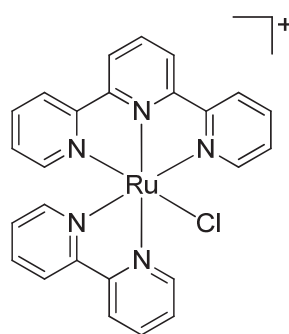

$[\mathrm{Ru}(\text { tpy })(\mathrm{bpy})(\mathrm{Cl})]^{+}(34)$

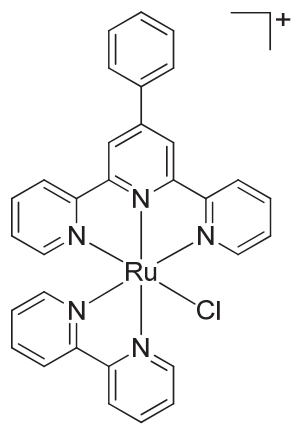

$[\mathrm{Ru}(\text { phtpy })(\mathrm{bpy})(\mathrm{Cl})]^{+}(35)$

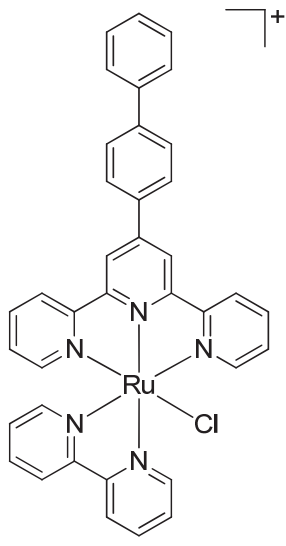

$[\mathrm{Ru}(\mathrm{biphtpy})(\mathrm{bpy})(\mathrm{Cl})]^{+}(36)$

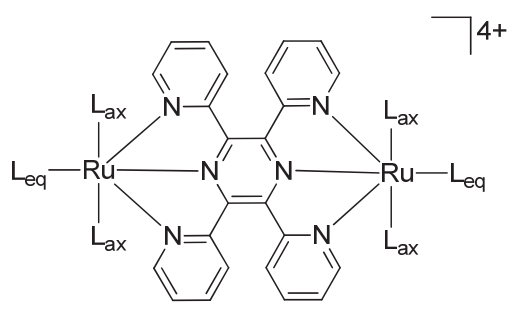

$\mathrm{L}_{\mathrm{ax}}=\mathrm{L}_{\mathrm{eq}}=\mathrm{CH}_{3} \mathrm{CN}$

$\left\{\left[\mathrm{Ru}\left(\mathrm{CH}_{3} \mathrm{CN}\right)_{3}\right]_{2}(\mathrm{tppz})\right\}^{4+}(\mathbf{3 7})$

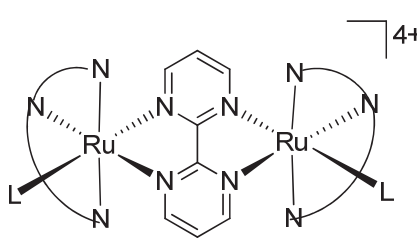

cis- $\left\{[\operatorname{Ru}(\mathrm{tpy})(\mathrm{L})]_{2}(\mathrm{bpm})\right\}^{4+}$

$\mathrm{L}=\mathrm{CH}_{3} \mathrm{CN}$ (38)

$\mathrm{L}=\mathrm{DMSO}(39)$

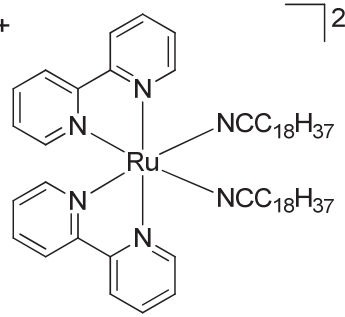

$\left[\mathrm{Ru}(\mathrm{bpy})_{2}\left(\mathrm{C}_{18} \mathrm{H}_{37} \mathrm{CN}\right)\right]^{2+}(\mathbf{4 0})$

图 9 长波长光活化 $\mathrm{Ru}(\mathrm{II})$ 多吡啶配合物

Figure 9 Long wavelength photoactivatable polypyridyl Ru(II) complexes 
了它们的细胞暗毒性, 发现 36 强的细胞暗毒性与其高 的细胞摄取能力紧密相关.

借助桥连配体构筑的双核或多核钉配合物, 其 MLCT 吸收带较相应单核配合物往往有显著的红 移 ${ }^{[70 ~ 72]}$. 该性质也被利用来构筑具有配体光解离活性 的配合物 37 39 ${ }^{[73]}$. 配合物 37 在 $610 \mathrm{~nm}$ 光照下处于轴 向的四个乙腈配体可以与溶剂分子发生交换反应, 处于 赤道面的 2 个乙腈配体则非常稳定. 对于配合物 38 和 39, 单齿配体为乙腈时, 配合物表现出高的光稳定性, 单齿配体为 DMSO 时, 光诱导单齿配体解离可有效发 生, 39 的 DMSO 光解离活性可能与 DMSO 的光致配位 异构作用有某种关联.

我们近期设计合成了以长链烷基腈类化合物为单齿 配体的钌(II)多吡啶配合物 $c i s-\left[\mathrm{Ru}(\mathrm{bpy})_{2}\left(\mathrm{C}_{18} \mathrm{H}_{37} \mathrm{CN}\right)_{2}\right]^{2+}$ (40), 借助长链烷烃间的范德华力相互作用将配合物成 功负载到油酸包覆的镧系元素掺杂的上转换纳米颗粒 $\left(\mathrm{LiYF}_{4}: 25 \% \mathrm{Yb}^{3+}, 0.5 \% \mathrm{Tm}^{3+}\right.$ ) 表面, 并通过表面超分子 组装 PEG 修饰的磷脂分子(DSPE-PEG-Methoxy)赋予纳 米复合体系在水溶液中良好的分散特性. 该复合体系在 避光条件下稳定, 在 $980 \mathrm{~nm}$ 激光 $\left(3 \mathrm{~W} / \mathrm{cm}^{2}\right)$ 照射下, 通 过两个单齿配体的解离, 实现活性物种 $\left[\mathrm{Ru}(\mathrm{bpy})_{2}\left(\mathrm{H}_{2} \mathrm{O}\right)_{2}\right]^{2+}$ 的释放及其与 DNA 的共价结合 ${ }^{[74]}$. 此外, Stavros 等 ${ }^{[75]}$ 利用双光子激发 $(800 \mathrm{~nm})$ 实现了配合 物 $c i s-\left[\mathrm{Ru}(\mathrm{bpy})_{2}(\mathrm{NA})_{2}\right]^{2+}(\mathbf{4 1})$ 中一个烟酰胺单齿配体的 解离.

\section{6 多功能钉光活化化疗试剂}

如前所述, 钉多吡啶配合物光致配体解离是经由 ${ }^{3} \mathrm{MLCT}$ 热活化布居到 ${ }^{3} \mathrm{MC}$ 实现的. 因此, 合理精细调 节 MLCT、MC 以及 LC 态(ligand-centered state)能级高 低, 理论上能够调控 MLCT 激发态各条失活路径的比 例, 从而赋予配合物多重功能.

Dunbar 和 Turro 两个团队 ${ }^{[76]}$ 在经典光致配体解离配 合物 $\left[\mathrm{Ru}(\mathrm{bpy})_{2}\left(\mathrm{CH}_{3} \mathrm{CN}\right)_{2}\right]^{2+}(3)$ 基础上, 引入具有低 ${ }^{3} \pi \pi^{*}$ 能级的 dppn 配体, 目标配合物 $[R u(b p y)(d p p n)-$ $\left.\left(\mathrm{CH}_{3} \mathrm{CN}\right)_{2}\right]^{2+}(42$, 图 10)在 $460 \mathrm{~nm}$ 光照条件下既能通过 ${ }^{3} \mathrm{MC}$ 态发生 $\mathrm{CH}_{3} \mathrm{CN}$ 配体解离, 生成水合物 $\left[\mathrm{Ru}(\mathrm{bpy})(\mathrm{dppn})\left(\mathrm{H}_{2} \mathrm{O}\right)_{2}\right]^{2+}(\Phi<1 \%)$, 也能通过布居到长 寿命的 ${ }^{3} \pi \pi^{*}(\mathrm{dppn})$ 态敏化产生 ${ }^{1} \mathrm{O}_{2}(\Phi=0.72$, 甲醇中结 果), 从而在单一分子中实现了光活化化疗与传统光动 力治疗的有机结合. 虽然 42 光致配体解离效率较低, 但 $\mathrm{HeLa}$ 细胞毒性实验结果显示其在 $466 \mathrm{~nm}$ 光照下的光毒 性因子 $\left(\mathrm{PI}=\mathrm{IC}_{50}{ }^{\text {dark }} / \mathrm{IC}_{50}{ }^{\text {light }}\right)$ 高达 1110 , 大大高于模型配 合物 $\left[\mathrm{Ru}(\mathrm{bpy})_{2}(\mathrm{dppn})\right]^{2+}(\mathrm{PI}=282)$ 及 $3(\mathrm{PI}=6.4)$.

Turro 小组 ${ }^{[77,78]}$ 进一步拓展此类配合物的研究. 通 过在 dppn 配体上引入甲基位阻基团, 降低了 ${ }^{3} \mathrm{MC}$ 态能 级, 从而提高了配体解离效率. $\left[\mathrm{Ru}(\mathrm{tpy})\left(\mathrm{Me}_{2} \mathrm{dppn}\right)(\mathrm{py})\right]^{2+}$
(43) 在 $\mathrm{CH}_{3} \mathrm{CN}$ 溶液中 $500 \mathrm{~nm}$ 光照条件下，单齿配体 py 解离效率提高到 $5.3 \%$, 单重态氧量子效率为 0.69 .

Turro 小组 ${ }^{[79]}$ 近期还报道了配 合 物 $[\mathrm{Ru}(\mathrm{pydppn})(\mathrm{biq})(\mathrm{py})]^{2+}(44)$, 其光诱导单齿吡啶配体的 解离效率为 $0.0070(500 \mathrm{~nm})$, 单重态氧量子效率为 0.75 .

在兼备光活化化疗和光动力治疗双重活性钉配合 物方面, 我们课题组 ${ }^{[80]}$ 也开展了一些有益的工作. 以吡 啶磺酸 $\left(\mathrm{py}-\mathrm{SO}_{3}\right)$ 双齿配体作为离去基团, 我们设计合成 了配合物 $\left[\mathrm{Ru}(\mathrm{bpy})_{2}\left(\mathrm{py}-\mathrm{SO}_{3}\right)\right]^{+}(\mathbf{4 5})$. 该配合物在 $355 \mathrm{~nm}$ 光照条件下, 双齿配体 $\mathrm{py}-\mathrm{SO}_{3}$ 能迅速解离, 生成可与 DNA 共价结合的水合物 $\left[\mathrm{Ru}(\mathrm{bpy})_{2}\left(\mathrm{H}_{2} \mathrm{O}\right)_{2}\right]^{2+}$. 此外, 部分 $\mathrm{Ru}-\mathrm{O}$ 键能以均裂的形式发生断裂, 生成 $\mathrm{py}-\mathrm{SO}_{3}$ ・自由 基. 该自由基具有很强反应活性，能在无氧条件下有效 断裂 DNA. 因此, $\mathbf{4 5}$ 在光照无氧条件下能以两种不同方 式有效损伤 DNA，有望对乏氧肿瘤实施有效杀伤. 进一 步的研究表明 bpy 配体上引入拉电子取代基时(如 $\left.\mathrm{COOCH}_{3}, 46\right)$, 能有效提高 $\mathrm{Ru}-\mathrm{O}$ 键均裂生成 $\mathrm{py}-\mathrm{SO}_{3}$ • 自由基的效率 ${ }^{[81]}$. 密度泛函理论计算表明 $\mathrm{Ru}-\mathrm{O}$ 键均 裂是经由 ${ }^{3} \sigma(\mathrm{Ru}-\mathrm{O}) \pi^{*}(\mathrm{R}-\mathrm{bpy})$ 激发态发生的, 而拉电子取 代基能有效降低 ${ }^{3} \sigma(\mathrm{Ru}-\mathrm{O}) \pi^{*}(\mathrm{R}-\mathrm{bpy})$ 激发态的能级, 从而 提高布居几率.

此外, 我们课题组还设计合成了一系列兼具光活化 化疗及光动力治疗功能的钌芳烃配合物, 统一归类到下 一部分(钉芳烃配合物)综述.

除了重点关注配体解离后生成的配位不饱和钉活 性组分外, 通过引入具有生物活性的可离去配体，同样 可以赋予此类配合物多重功能.

Dunbar 和 Turro 两团队 ${ }^{[82]}$ 利用化疗药物 5-氟尿嘧啶 (5FU)的衍生物 5-氧基尿嘧啶(5CNU)作为离去配体，设 计合成了 $\left[\mathrm{Ru}(\mathrm{bpy})_{2}(5 \mathrm{CNU})_{2}\right]^{2+}(47)$, 在大于 $395 \mathrm{~nm}$ 光 照下能释放 2 分子的 $5 \mathrm{CNU}$ 以及 1 分子能和 DNA 共价 结合的 $\left[\mathrm{Ru}(\mathrm{bpy})_{2}\left(\mathrm{H}_{2} \mathrm{O}\right)_{2}\right]^{2+}$. 在此基础上, 他们 ${ }^{[83]}$ 将这一 思路拓展到 $\mathrm{Ru}(\mathrm{tpy})$ 体系, 合成了 $\left[\mathrm{Ru}(\mathrm{tpy})(5 \mathrm{CNU})_{3}\right]^{2+}$ (48), 在 $400 \mathrm{~nm}$ 光照下能释放 2 分子 $5 \mathrm{CNU}$ 及 1 分子 $\left[\mathrm{Ru}(\mathrm{tpy})(5 \mathrm{CNU})\left(\mathrm{H}_{2} \mathrm{O}\right)_{2}\right]^{2+}$. 然而细胞毒性实验结果显示 48 在大于 $400 \mathrm{~nm}$ 光照 $1 \mathrm{~h}$ 条件下呈现出与同浓度自由 $5 \mathrm{CNU}$ 配体相似的细胞毒性, 作者将其归属为 48 在细胞 实验条件下只有一个 $5 \mathrm{CNU}$ 配体发生解离, 且生成的单 水合物 $\left[\mathrm{Ru}(\mathrm{tpy})(5 \mathrm{CNU})_{2}\left(\mathrm{H}_{2} \mathrm{O}\right)\right]^{2+}$ 并不能和 DNA 共价结 合.

Podgorski、Turro 和 Kodanko ${ }^{[84]}$ 合作研究了配合物 $\left[\mathrm{Ru}(\mathrm{bpy})_{2}\left(\mathrm{Ac}-\mathrm{Phe}-\mathrm{NHCH}_{2} \mathrm{CN}\right)_{2}\right]^{2+}(49)$, 其离去配体 Ac-Phe- $\mathrm{NHCH}_{2} \mathrm{CN}$ 是半胱氨酸蛋白酶抑制剂. 半胱氨酸 蛋白酶在许多肿瘤组织过度表达，与肿瘤的生长、转移 以及血管生成都有密切关系, 是肿瘤治疗的一个潜在靶 点. 49 在大于 $395 \mathrm{~nm}$ 光照下能迅速释放 2 分子蛋白酶抑 制剂及 1 分子 $\left[\mathrm{Ru}(\mathrm{bpy})_{2}\left(\mathrm{H}_{2} \mathrm{O}\right)_{2}\right]^{2+}$. 细胞外蛋白酶抑 


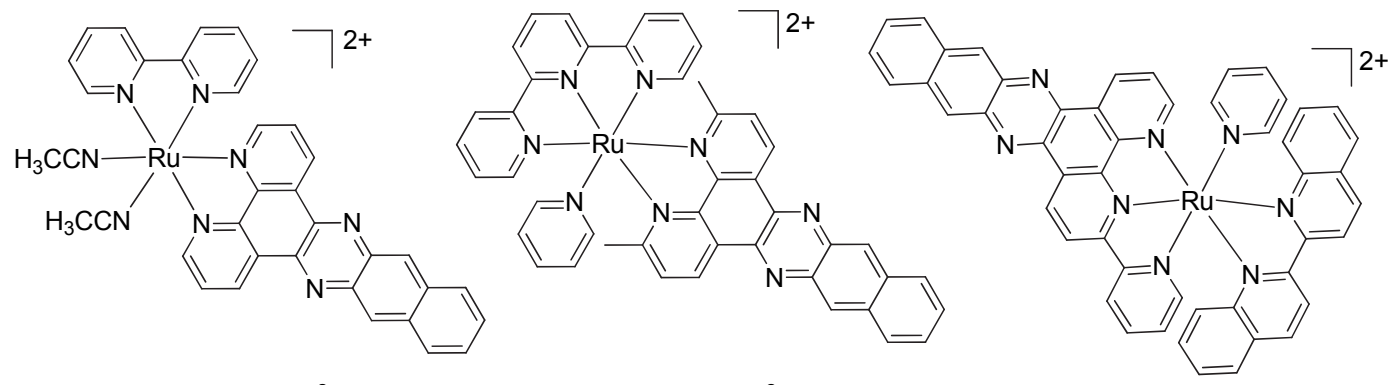

$\left[\mathrm{Ru}(\mathrm{bpy})(\mathrm{dppn})\left(\mathrm{CH}_{3} \mathrm{CN}\right)_{2}\right]^{2+}(\mathbf{4 2}) \quad\left[\mathrm{Ru}(\mathrm{tpy})\left(\mathrm{Me}_{2} \mathrm{dppn}\right)(\mathrm{py})\right]^{2+}(\mathbf{4 3})$

$\left[\operatorname{Ru}(\text { pydppn)(biq)(py) }]^{2+}(\mathbf{4 4})\right.$

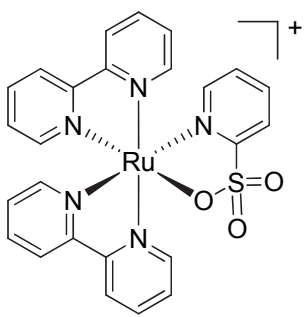

$\left[\mathrm{Ru}(\mathrm{bpy})_{2}\left(\mathrm{py}-\mathrm{SO}_{3}\right)\right]^{+}(\mathbf{4 5})$

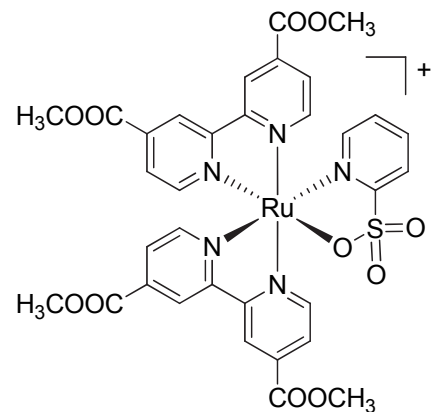

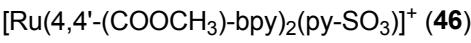

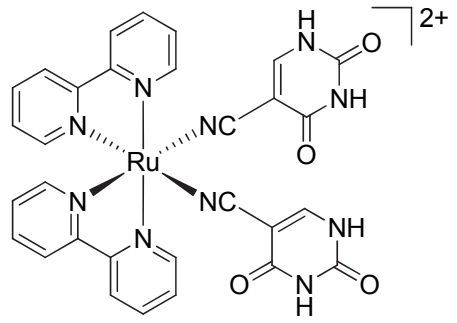

$\left[\mathrm{Ru}(\mathrm{bpy})_{2}(5 \mathrm{CNU})_{2}\right]^{2+}(47)$

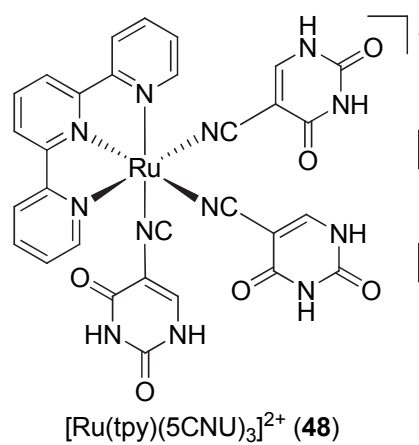

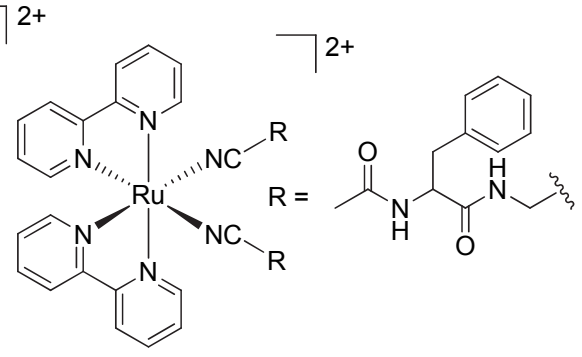

$\left[\mathrm{Ru}(\mathrm{bpy})_{2}\left(\mathrm{Ac}-\mathrm{Phe}-\mathrm{NHCH}_{2} \mathrm{CN}\right)_{2}\right]^{2+}(\mathbf{4 9})$<smiles></smiles>

$\left[\mathrm{Ru}(\mathrm{bpy})_{2}(\text { py-N=N-py })_{2}\right]^{2+}(\mathbf{5 0})$

图 10 多功能钓光活化化疗试剂

Figure $10 \mathrm{Ru}(\mathrm{II}) \mathrm{PACT}$ agents with multiple functions

制实验表明 49 在光照条件下 $\mathrm{IC}_{50}$ 值是自由配体 Ac-Phe- $\mathrm{NHCH}_{2} \mathrm{CN}$ 的 $1 / 2$, 且其对组织蛋白酶 B、 $\mathrm{K}$ 和 $\mathrm{L}$ 的 $\mathrm{IC}_{50}{ }^{\mathrm{dark}} / \mathrm{IC}_{50}{ }^{\text {light }}$ 比值在 $6: 1 \sim 33: 1$. 遗憾的是, 本文 作者并没有对 $\left[\mathrm{Ru}(\mathrm{bpy})_{2}\left(\mathrm{H}_{2} \mathrm{O}\right)_{2}\right]^{2+}$ 是否具有蛋白酶抑制 活性进行探讨. 此外, 细胞及 $3 \mathrm{D}$ 组织模型实验中 49 表 现出很好的光诱导蛋白酶抑制活性 ${ }^{[85,86]}$.

虽然光活化过程在很大程度上已经能够有效地提 高药物的选择性, 但是不必要的光照, 例如太阳光等, 依然会活化正常组织内存留的光活化药物, 从而引发毒 副作用. 我们课题组 ${ }^{[87]}$ 通过在离去配体 py 上修饰偶氮 基团, 设计合成出具有谷胱甘肽(GSH)响应的光活化化 疗试剂 $\left[\mathrm{Ru}(\mathrm{bpy})_{2}(\mathrm{py}-\mathrm{N}=\mathrm{N}-\mathrm{py})_{2}\right]^{2+}(\mathbf{5 0})$. 偶氮基团可有效 猝灭 ${ }^{3} \mathrm{MLCT}$ 态, 阻止 ${ }^{3} \mathrm{MC}$ 态的布居, 从而使得目标配 合物光照条件下非常稳定; 当偶氮基团被 GSH 还原后, 还原产物重新恢复光致配体解离活性. 肿瘤组织内 GSH 浓度通常是正常组织的数倍, 也被认为是肿瘤组 织的一个潜在靶点. 此类 GSH 响应的光活化化疗试剂 对肿瘤细胞具有更高的选择性.

\section{7 钉芳烃配合物}

前述的 $\mathrm{Ru}$ 光活化化疗试剂均为钓多吡啶配合物, 还有一大家族的 $\mathrm{Ru}$ 配合物在化疗乃至光活化化疗试剂 方面展现出诱人的前景, 这就是钓芳烃配合物. 它们具 有通式 $\left[\left(\eta^{6} \text {-arene }\right) \mathrm{Ru}(\mathrm{L})(\mathrm{X})\right]^{n+}$ [其中 $\mathrm{L}$ 为双齿配体, $\mathrm{X}$ 为 离去配体(通常为卤素)], 空间上呈现 “钢琴登” 结构, 其 中芳烃构成 “登面”，L和 X 构成三个 “登腿”。这类 配合物的抗肿瘤活性通常被认为是来自于 $\mathrm{X}$ 配体解离 后生成的水合物. 当 $\mathrm{X}$ 为卤素时, $\mathrm{X}$ 配体解离是自发且 不可控的. 通过将 $\mathrm{X}$ 配体换成配位能力更强的单齿配 体, 例如吡啶及其衍生物, 以及对 L 双齿配体和芳香环 进行合理设计, 也能获得具有光活化化疗活性的前药.

Sadler 小组 ${ }^{[88} 2007$ 年报道了系列钓芳烃双核配合 物(51, 图 11), 其中芳烃配体为茆满或者苯的双核配合 物在 UVA 光照下能发生芳烃配体的解离, 生成的水合 物能和 DNA 发生明显的链间交联. 对照实验显示相应 化合物在黑暗条件下只能与 DNA 发生微弱的相互作用. 但这类配合物较短的激发波长限制了其实际应用. 


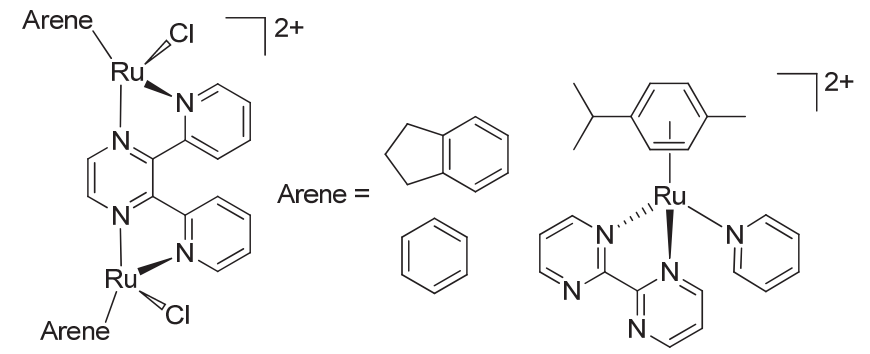

$\left[\left\{(\text { arene }) \mathrm{RuCl}_{2}(u-2,3-\mathrm{dpp})\right]^{2+}(\right.$ 51)

$[(p-\text { cym }) \operatorname{Ru}(\text { bpm })(\text { py })]^{2+}(\mathbf{5 2})$

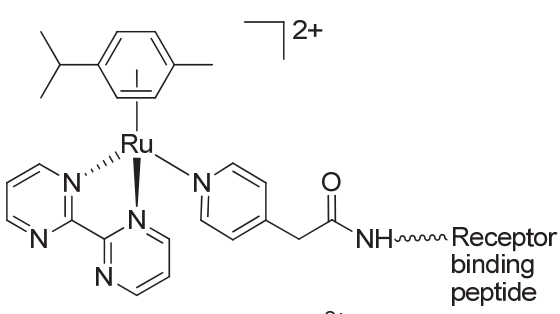

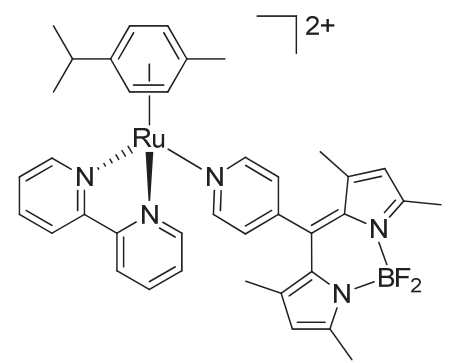

$[(p-c y m) R u(\text { bpy })(\text { py-BODIPY })]^{2+}(54)$

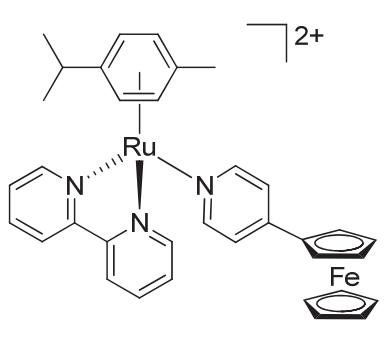

$[(p-c y m) R u(b p y)(p y-F c)]^{2+}(55)$ $\left[(p-c y m) R u(b p m)(\text { peptide-py) }]^{2+}(53)\right.$

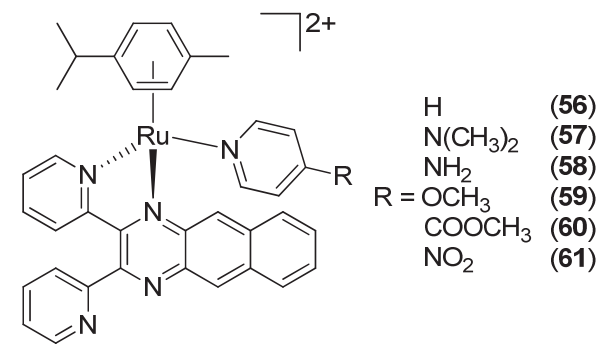

$[(p-c y m) R u(d p b)(p y-R)]^{2+}$

图 11 钓芳烃配合物光活化化疗试剂

Figure $11 \mathrm{Ru}(\mathrm{II})$ arene complex-based PACT agents

Sadler 小组 ${ }^{[89]}$ 进一步通过引入缺电子的 bpm 双齿配 体, 设计合成了 $[(p-c y m) R u(b p m)(p y)]^{2+}(\mathbf{5 2})$, 该配合物 在可见光 $(400 \sim 600 \mathrm{~nm})$ 激发下, 单齿配体吡啶发生解 离, 生成的水合物 $\left[(p-c y m) R u(b p m)\left(\mathrm{H}_{2} \mathrm{O}\right)\right]^{2+}$ 能和鸟嘌呤 结合. 在此基础上, 他们 ${ }^{[00]}$ 进一步在吡啶配体上修饰肿 瘤靶向因子 $(\mathbf{5 3})$, 以提高药物对肿瘤组织的主动靶向. 在可见光 $(400 \sim 600 \mathrm{~nm})$ 激发下, 单齿配体发生解离, 生 成的水合物能和 DNA 序列中的鸟嘌呤共价结合. 有趣 的是，在有塞聚 DNA 存在条件下，该配合物能发生芳 烃配体的光致解离, 生成的多水合物能和两个鸟嘌呤同 时共价结合.

我们课题组 ${ }^{[91]}$ 在基于钉芳烃配合物的光活化化疗 药物方面也开展了许多工作. 通过在 py 配体上修饰 BODIPY 基团, 设计合成了 $[(p$-cym $) \mathrm{Ru}(\mathrm{bpy})-$ $(\text { py-BODIPY) }]^{2+}(54)$. BODIPY 基团的引入有效红移配 合物的吸收波长至 $500 \mathrm{~nm}$ 以上. 有趣的是选择性的光 激发 $(>500 \mathrm{~nm})$ BODIPY, 单齿配体 py-BODIPY 能迅速 发生解离, 生成的水合物 $\left[(p-c y m) \mathrm{Ru}(\mathrm{bpy})\left(\mathrm{H}_{2} \mathrm{O}\right)\right]^{2+}$ 能和 鸟嘌呤共价结合. 详细的机理研究表明, py-BODIPY 向 $\mathrm{Ru}$ 芳烃部分发生的光致电子转移是导致单齿配体解离 的主要原因, 这一全新的配体解离机制为有效红移光活 化波长提供了新思路.

基于上述研究结果, 我们进一步通过在钓芳烃配合 物的单齿配体上引入具有氧化还原活性的二茂铁基团, 设计合成了 $[(p \text {-cym }) \operatorname{Ru}(\mathrm{bpy})(\mathrm{py}-\mathrm{Fc})]^{2+}(\mathbf{5 5})^{[92]}$. 二茂铁基 团的引入使得目标配合物的吸收波长红移至 $500 \sim 600$ $\mathrm{nm}$ 区域. 可见光激发下单齿配体 py-Fc 发生解离, 由二 茂铁至钓芳烃部分的光诱导电子转移作用对配体解离 做出了贡献. 此外, 二茂铁基团的引入还赋予目标配合
物差基自由基 $(\cdot \mathrm{OH})$ 及 ${ }^{1} \mathrm{O}_{2}$ 产生能力, 在简单钓芳烃配合 物中实现了光活化化疗与传统光动力治疗的有机结合.

我们课题组 ${ }^{[93]}$ 还通过引入具有大 $\pi$ 共轭体系的 $\mathrm{dpb}$ 配体, 赋予配合物 $[(p-c y m) R u(d p b)(p y)]^{2+}(\mathbf{5 6})$ 多重功能: (1) $\mathrm{dpb}$ 配体低的 $\pi^{*}$ 轨道能有效红移配合物的吸收波长 至 500 600 nm 区域; (2) dpb 配体较低且长寿命的 ${ }^{3} \pi \pi^{*}$ 能级可有效敏化产生 ${ }^{1} \mathrm{O}_{2}$ ( $\Phi_{480}=0.25$, 乙腈中结果); (3) $\mathrm{dpb}$ 配体大的位阻效应使配合物光激发下不仅能发生单 齿配体解离, 也能发生 $\mathrm{dpb}$ 双齿配体解离; (4) 解离后的 $\mathrm{dpb}$ 配体有强苂光, 可以利用其检测药物在细胞内的分 布定位. 细胞苂光共聚焦实验表明, 该配合物能选择性 定位在细胞核中. 细胞毒性实验表明, 该配合物光照条 件下能有效杀伤 A549 细胞, 光毒性因子 PI 值为 6.9.

在上述工作基础上，我们 ${ }^{[94]}$ 进一步通过在单齿配 体吡啶上引入推拉电子基团(57 61) 来调控配合物的光 物理光化学性质. 拉电子基团的引入能有效提高配合物 的 ${ }^{1} \mathrm{O}_{2}$ 量子效率, 其中 $\mathrm{NO}_{2}$ 基团取代的配合物 61 的 ${ }^{1} \mathrm{O}_{2}$ 量子效率高达 0.39 (乙腈溶液中测得). 与此同时, 拉电子 取代基也能提高光致配体解离效率, 增强其与 DNA 的 共价结合能力. 然而细胞实验显示 $\mathbf{5 6}$ 的光毒性因子最 高, 可能原因是其在水溶液中具有最高的 ${ }^{1} \mathrm{O}_{2}$ 量子效率.

\section{8 展望}

钉光活化化疗试剂研究是近年来金属类抗癌药物 研发领域的一个研究热点. 随着研究的不断深入, 对具 备光活化化疗活性的钉配合物的构效关系已有了初步 的认识, 然而该类试剂目前的药物性能与临床应用尚有 较大的距离, 还需要研究者们在如下多个方面继续深入 探究. 
光活化波长有待进一步延长, 在已报道的钓光活化 化疗试剂中, 还没有哪一个配合物的 MLCT 最大吸收波 长位于光疗窗口之内.

延长 MLCT 吸收波长的一个常见结果是增加了 ${ }^{3} \mathrm{MLCT}$ 态与 ${ }^{3} \mathrm{MC}$ 态的能隙, 这无疑会降低配体解离效 率, 如何在延长活化波长的同时, 不降低甚至能够提高 配体解离效率, 是一个挑战性的工作.

光敏剂配体可能是面对这一挑战的有效策略，通过 从光敏剂配体到钓配合物的光诱导电子转移作用, 使光 敏剂配体带上正电荷, 可以显著削弱其配位能力, 有望 在延长光活化波长的同时增强配体解离效率. 虽然这一 策略已得到验证 ${ }^{[91,92]}$, 但所用光敏剂吸收光谱处于绿光 范围, 还需进一步红移.

上转换纳米颗粒的应用也是方案之一, 但它们的上 转换效率有待进一步提升, 以避免过强近红外光的使用 对生物组织的直接损伤. 此外, 目前常见的上转换纳米 颗粒激发波长均为 $980 \mathrm{~nm}$, 水分子对其吸收导致的热 效应非常显著 ${ }^{[95]}$.

作为药物分子, 细胞摄取及其亚细胞器定位能力是 衡量其活性的重要指标, 然而在光活化化疗药物领域, 这方面的研究还极为缺乏. 事实上, 许多具有配体光解 离活性的钓配合物呈现出非常低的细胞毒性, 因此常被 作为药物载体加以应用 ${ }^{[34 \sim 42]}$, 这很可能源于配合物不 同的亚细胞器定位能力, 而这不仅与离去配体相关联, 辅配体可能起到更为重要的作用. 目前的研究多聚焦于 离去配体结构与其光解离效率的依赖关系, 很少关注辅 助配体结构对配合物的 DNA 结合、细胞摄取、亚细胞 器定位以及细胞光毒性和暗毒性的影响, 进一步强化该 方面的研究有望促进钓配合物光活化抗癌药物活性的 提升.

在钓光活化化疗试剂的已有报道中, 多以 DNA 为 其药物活性研究对象, 细胞水平甚至动物活体水平的研 究仅占少数, 更谈不上深入研究这类药物的真实抗癌机 制. 绝大多数的钓配合物是不能进入细胞核的, 那么它 们光活化抗癌靶点是否遵循非 DNA 机制? 深入开展这 方面的研究, 无疑有助于催生新的药物分子设计理念.

\section{作者简介}

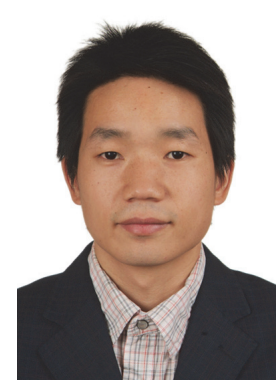

周前雄, 2010 年于中国科学院理化技术研究所获得博士 学位并留所工作, 目前任副研究员, 主要从事金属配合物光 动力抗肿瘤以及光动力抗菌方面的研究.

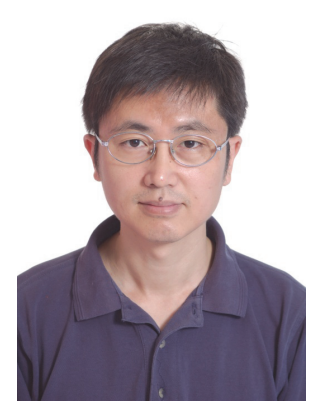

王雪松, 中国科学院理化技术研究所研究员、博士生导师. 主要从事药物及药物中间体的光化学合成以及光疗药物设计 合成及其机理研究.

\section{References}

[1] Romero-Canelón, I.; Sadler, P. J. Inorg. Chem. 2013, 52, 12276.

[2] Mjos, K. D.; Orvig, C. Chem. Rev. 2014, 114, 4540.

[3] Gaynor, D.; Griffith, D. M. Dalton Trans. 2012, 41, 13239.

[4] Liu, Y.; Chen, X.; Zhang, L.; Sun, D.; Zhou, Y.; Chen, L.; Liu, J. Acta Chim. Sinica 2014, 72, 473 (in Chinese). (刘荣, 陈小曼, 张郎 棋, 孙冬冬, 周艳晖, 陈兰美, 刘杰, 化学学报, 2014, 72, 473.)

[5] Zhou, S.; Xue, X.; Jiang, B.; Lu, C.; Tian, Y.; Jiang, M. Acta Chim. Sinica 2011, 69, 2335 (in Chinese). (周双生，薛璇，姜波，鲁传华， 田玉鹏，蒋明华，化学学报, 2011, 69, 2335.)

[6] Xia, Q.; He, Q.; Xu, D.; Li, X.; Sun, D. Acta Chim. Sinica 2010, 68, 775 (in Chinese). (夏庆春, 何其庄, 许东芳, 李兴玉, 孙大志, 化 学学报, 2010, 68, 775.)

[7] Yin, F.-L.; Shen, J.; Zou, J.-J.; Li, R.-C.; Acta Chim. Sinica 2003 61,556 (in Chinese). (尹富玲, 申佳, 邹佳嘉, 李荣昌, 化学学报, 2003, 61, 556.)

[8] Rosenberg, B.; Vancamp, L.; Krigas, T. Nature 1965, 205, 698.

[9] Rosenberg, B.; VanCamp, L.; Trosko, J. E.; Mansour, V. H. Nature $1969,222,385$.

[10] Wheate, N. J.; Walker, S.; Craig, G. E.; Oun, R. Dalton Trans. 2010 , 39,8113

[11] Bugarčić, Ž. D.; Bogojeski, J.; Petrović, B.; Hochreuther, S.; van Eldik, R. Dalton Trans. 2012, 41, 12329.

[12] Fanelli, M.; Formica, M.; Fusi, V.; Giorgi, L.; Micheloni, M.; Paoli, P. Coord. Chem. Rev. 2016, 310, 41.

[13] Johnstone, T. C.; Suntharalingam, K.; Lippard, S. J. Chem. Rev. 2016, $116,3436$.

[14] Mackay, F. S.;Woods, J. A.; Heringova, P.; Kašpárková, J.; Pizarro, A. M.; Moggach, S. A.; Parsons, S.; Brabec, V.; Sadler, P. J. Proc. Natl. Acad. Sci. U. S. A. 2007, 104, 20743.

[15] Farrer, N. J.; Woods, J. A.; Salassa, L.; Zhao, Y.; Robinson, K. S.; Clarkson, G.; Mackay, F. S.; Sadler, P. J. Angew. Chem. Int. Ed. 2010, 49, 8905.

[16] Kasparkova, J.; Kostrhunova, H.; Novakova, O.; Křikavová, R.; Vančo, J.; Trávníčk, Z.; Brabec, V. Angew. Chem. Int. Ed. 2015, 54, 14478.

[17] Glazer, E. C. Isr. J. Chem. 2013, 53, 391.

[18] Farrer, N. J.; Salassa, L.; Sadler, P. J. Dalton Trans. 2009, 10690.

[19] Detty, M. R.; Gibson, S. L.; Wagner, S. J. J. Med. Chem. 2004, 47, 3897.

[20] Brown, J. M.; Wilson, W. R. Nat. Rev. Cancer 2004, 4, 437.

[21] Minchinton, A. I.; Tannock, I. F. Nat. Rev. Cancer 2006, 6, 583.

[22] Knoll, J. D.; Turro, C. Coord. Chem. Rev. 2015, 282-283, 110.

[23] Gianferrara, T.; Bratsos, I.; Alessio, E. Dalton Trans. 2009, 7588.

[24] Lincoln, R.; Kohler, L.; Monro, S.; Yin, H.; Stephenson, M.; Zong, R.; Chouai, A.; Dorsey, C.; Hennigar, R.; Thummel, R. P.; McFarland, S. A. J. Am. Chem. Soc. 2013, 135, 17161.

[25] Sun, Y.; Joyce, L. E.; Dickson, N. M.; Turro, C. Chem. Commun. 2010, 46,2426 .

[26] Zhou, Q. X.; Lei, W. H.; Chen, J. R.; Li, C.; Hou, Y. J.; Wang, X. S.; Zhang, B. W. Chem.-Eur. J. 2010, 16, 3157.

[27] Zhou, Q. X.; Lei, W. H.; Sun, Y.; Chen, J. R.; Li, C.; Hou, Y. J.; Wang, X. S.; Zhang, B. W. Inorg. Chem. 2010, 49, 4729.

[28] Zhou, Q. X.; Yang, F.; Lei, W. H.; Chen, J. R.; Li, C.; Hou, Y. J.; Ai, X. C.; Zhang, J. P.; Wang, X. S.; Zhang, B. W. J. Phys. Chem. B 
2009, 113, 11521 .

[29] Liu, Y.; Hammitt, R.; Lutterman, D. A.; Joyce, L. E.; Thummel, R. P.; Turro, C. Inorg. Chem. 2009, 48, 375.

[30] Poteet, S. A.; Majewski, M. B.; Breitbach, Z. S.; Griffith, C. A.; Singh, S.; Armstrong, D. W.; Wolf, M. O.; MacDonnell, F. M. J. Am. Chem. Soc. 2013, 135, 2419.

[31] Vanderlinden, W.; Blunt, M.; David, C. C.; Moucheron, C.; Kirsch-De Mesmaeker, A.; De Feyter, S. J. Am. Chem. Soc. 2012, 134, 10214.

[32] Boggio-Pasqua, M.; Vicendo, P.; Oubal, M.; Alary, F.; Heully, J.-L. Chem.-Eur. J. 2009, 15, 2759.

[33] Lecomte, J.-P.; Kirsch-De Mesmaeker, A.; Feeney, M. M.; Kelly, J. M. Inorg. Chem. 1995, 34, 6481.

[34] Zayat, L.; Calero, C.; Alborés P.; Baraldo, L.; Etchenique, R. J. Am. Chem. Soc. 2003, 125, 882 .

[35] Bonnet, S.; Limburg, B.; Meeldijk, J. D.; Klein Gebbink, R. J. M.; Killian, J. A. J. Am. Chem. Soc. 2011, 133, 252.

[36] Respondek, T.; Garner, R. N.; Herroon, M. K.; Podgorski, I.; Turro, C.; Kodanko, J. J. J. Am. Chem. Soc. 2011, 133, 17164.

[37] Miguel, V. S.; Álvarez, M.; Filevich, O.; Etchenique, R.; del Campo, A. Langmuir 2012, 28, 1217.

[38] Mosquera, J.; Sánchez, M. R.; Mascareñas, J. L.; Vázquez, M. E. Chem. Commun. 2015, 51, 5501 .

[39] Nakanishi, K.; Koshiyama, T.; Iba, S.; Ohba, M. Dalton Trans. 2015, $44,14200$.

[40] Griepenburg, J. C.; Rapp, T. L.; Carroll, P. J.; Eberwineb, J.; Dmochowski, I. J. Chem. Sci. 2015, 6, 2342.

[41] Li, A.; White, J. K.; Arora, K.; Herroon, M. K.; Martin, P. D.; Bernhard Schlegel, H.; Podgorski, I.; Turro, C.; Kodanko, J. J. Inorg. Chem. 2016, 55, 10.

[42] Sharma, R.; Knoll, J. D.; Ancona, N.; Martin, P. D.; Turro, C.; Kodanko, J. J. Inorg. Chem. 2015, 54, 1901.

[43] Ford, P. C. Coord. Chem. Rev. 1982, 44, 61.

[44] Tfouni, E. Coord. Chem. Rev. 2000, 196, 281

[45] Van Houten, J.; Watts, R. J. Inorg. Chem. 1978, 17, 3381.

[46] Durante, V. A.; Ford, P. C. Inorg. Chem. 1979, 18, 588.

[47] Singh, T. N.; Turro, C. Inorg. Chem. 2004, 43, 7260.

[48] Rillema, D. P.; Blanton, C. B.; Shaver, R. J.; Jackman, D. C.; Boldaji, M.; Bundy, S.; Worl, L. A.; Meyer, T. J. Inorg. Chem. 1992, 31, 1600 .

[49] Liu, Y.; Turner, D. B.; Singh, T. N.; Angeles-Boza, A. M.; Chouai, A.; Dunbar, K. R.; Turro, C. J. Am. Chem. Soc. 2009, 131, 26.

[50] Arora, K.; White, J. K. Sharma, R.; Mazumder, S.; Martin, P. D.; Schlegel, H. B.; Turro, C.; Kodanko, J. K. Inorg. Chem. 2016, 55, 6968.

[51] Knoll, J. D.; Albani, B. A.; Durr, C. B.; Turro, C. J. Phys. Chem. A 2014, 118, 10603.

[52] Albani, B. A.; Durr, C. B.; Turro, C. J. Phys. Chem. A 2013, 117, 13885.

[53] Garner, R. N.; Joyce, L. E.; Turro, C. Inorg. Chem. 2011, 50, 4384.

[54] Howerton, B. S.; Heidary, D. K.; Glazer, E. C. J. Am. Chem. Soc. 2012, 134, 8324.

[55] Hidayatullah, A. N.; Wachter, E.; Heidary, D. K.; Parkin, S.; Glazer, E. C. Inorg. Chem. 2014, 53, 10030.

[56] Wachter, E.; Heidary, D. K.; Howerton, B. S.; Parkin, S.; Glazer, E. C. Chem. Commun. 2012, 48, 9649.

[57] Dickerson, M.; Howerton, B.; Baeb, Y.; Glazer, E. C. J. Mater. Chem. B 2016, 4, 394.

[58] Friedman, A. E.; Chambron, J.-C.; Sauvage, J.-P.; Turro, N. J.; Barton, J. K. J. Am. Chem. Soc. 1990, 112, 4960.

[59] Wachter, E.; Howerton, B. S.; Hall, E. C.; Parkin, S.; Glazer, E. C. Chem. Commun. 2014, 50, 311.

[60] Wachter, E.; Glazer, E. C. J. Phys. Chem. A 2014, 118, 10474.

[61] Wachter, E.; Moyá, D.; Parkin, S.; Glazer, E. C. Chem.-Eur. J. 2016, 22,550 .

[62] Cleare, M. J.; Hoeschele, J. D. Bioinorg. Chem. 1973, 2, 187.

[63] Farrell, N. Transition Metal Complexes as Drugs and Chemotherapeutic Agents, Kluwer, Dordrecht, Netherlands, 1989.

[64] Van Rixel, V. H. S; Siewert, B.; Hopkins, S. L.; Askes, S. H. C.; Busemann, A.; Siegler, M. A.; Bonnet, S. Chem. Sci. 2016, 7, 4922.

[65] Wachter, E.; Zamora, A.; Heidary, D. K.; Ruizb, J.; Glazer, E. C.
Chem. Commun. 2016, 52, 10121

[66] Dąbrowski, J. M.; Arnaut, L. G. Photochem. Photobiol. Sci. 2015 14,1765

[67] Sears, R. B.; Joyce, L. E.; Ojaimi, M.; Gallucci, J. C.; Thummel, R. P.; Turro, C. J. Inorg. Biochem. 2013, 121, 77.

[68] Albani, B. A.; Peña, B.; Dunbar, K. R.; Turro, C. Photochem. Photobiol. Sci. 2014, 13, 272

[69] Huang, H.; Zhang, P.; Chen, Y.; Ji, L.; Chao, H. Dalton Trans. 2015, 44, 15602.

[70] Ruminski, R. R.; Degroff, C.; Smith, S. J. Inorg. Chem. 1992, 31, 3325 .

[71] Rillema, D. P.; Mack, K. B. Inorg. Chem. 1982, 21, 3849.

[72] Ernst, S.; Kasack, V.; Kaim, W. Inorg. Chem. 1988, 27, 1146.

[73] Albani, B. A.; Peña, B.; Saha, S.; White, J. K.; Schaeffer, A. M.; Dunbar, K. R.; Turro, C. Chem. Commun. 2015, 51, 16522.

[74] Chen, Y.; Jiang, G.; Zhou, Q.; Zhang, Y.; Li, K.; Zheng, Y.; Zhang, B.; Wang, X. RSC Adv. 2016, 6, 23804.

[75] Greenough, S. E.; Horbury, M. D.; Smith, N. A.; Sadler, P. J.; Paterson, M. J.; Stavros, V. G. ChemPhysChem 2016, 17, 221.

[76] Albani, B. A.; Peña, B.; Leed, N. A.; Paula, N. A. B. G. D.; Pavani, C.; Baptista, M. S.; Dunbar, K. R.; Turro, C. J. Am. Chem. Soc. 2014, 136, 17095.

[77] Knoll, J. D.; Albani, B. A.; Turro, C. Chem. Commun. 2015, 51, 8777.

[78] Knoll, J. D.; Albani, B. A.; Turro, C. Acc. Chem. Res. 2015, 48 , 2280.

[79] Loftus, L. M.; White, J. K.; Albani, B. A.; kohler, L.; Kodanko, J. K.; Thummel, R. P.; Dunba, K. R.; Turro, C. Chem.-Eur. J. 2016, 22, 3704.

[80] Zheng, Y.; Zhou, Q.-X.; Lei, W.-H.; Hou, Y.-J.; Li, K.; Chen, Y.-J.; Zhang, B.-W.; Wang, X.-S. Chem. Commun. 2015, 51, 428.

[81] Zheng, Y.; Zhou, Q.-X.; Zhang, Y.-Y.; Li, C.; Hou, Y.-J.; Wang, X.-S. Dalton Trans. 2016, 45, 2897.

[82] Gamer, B. N.; Gallucci, J. C.; Dunbar, K. R.; Turro, C. Inorg. Chem. 2011, 50, 9213

[83] Sgambellone, M. A.; David, A.; Garner, R. N.; Dunbar, K. R.; Turro, C. J. Am. Chem. Soc. 2013, 135, 11274.

[84] Respondek, T.; Garmer, R. N.; Herroon, M. K.; Podgorski, I.; Turro, C.; Kodanko, J. J. J. Am. Chem. Soc. 2011, 133, 17164.

[85] Respondek, T.; Sharma, R.; Herroon, M. K.; Garmer, R. N.; Knoll, J. D.; Cueny, E.; Turro, C.; Podgorski, I.; Kodanko, J. J. ChemMedChem 2014, 9, 1306.

[86] Ramalho, S. D.; Sharma, R.; White, J. K.; Aggarwal, N.; Chalasani, A.; Sameni, M.; Moin, K.; Vieira, P. C.; Turro, C.; Kodanko, J. J.; Sloane, B. F. Plos One 2015, DOI:10.1371/journal.pone.0142527

[87] Zhou, Q.-X.; Zheng, Y.; Wang, T.-J.; Chen, Y.-J.; Li, K.; Zhang, Y.-Y.; Li. C.; Hou, Y.-J.; Wang, X.-S. Chem. Commun. 2015, 51, 10684.

[88] Magennis, S. W.; Habtemariam, A.; Novakova, O.; Henry, J. B.; Meier, S.; Parsons, S.; Oswald, L. D. H.; Brabec, V.; Sadler, P. J. Inorg. Chem. 2007, 46, 5059.

[89] Betanzos-Lara, S.; Salassa, L.; Habtemariam, A.; Sadler, P. J. Chem Commun. 2009, 43, 6622

[90] Barragán, F.; López-Senín, P.; Salassa, L.; Betanzos-Lara, S.; Habtemariam, A.; Moreno, V.; Sadler, P. J.; Marchán, V. J. Am. Chem. Soc. 2011, 133, 14098.

[91] Zhou, Q.-X.; Lei, W.-H.; Hou, Y.-J.; Chen, Y.-J.; Li, C.; Zhang, B.-W.; Wang, X.-S. Dalton Trans. 2013, 42, 2786.

[92] Wang, T.-J.; Zhou, Q.-X.; Zhang, Y.-Y.; Zheng, Y.; Wang, W.-B.; Hou, Y.-J.; Jiang, G.-Y.; Cheng, X.-X.; Wang, X.-S. RSC Adv. 2016, $6,45652$.

[93] Chen, Y.-J.; Lei, W.-H.; Jiang, G.-Y.; Hou, Y.-J.; Li, C.; Zhang, B.-W.; Zhou, Q.-X.; Wang, X.-S. Dalton Trans. 2014, 43, 15375.

[94] Chen, Y.-J.; Lei, W.-H.; Hou, Y.-J.; Li, C.; Jiang, G.-Y.; Zhang, B.-W.; Zhou, Q.-X.; Wang, X.-S. Dalton Trans. 2015, 44, 7347.

[95] Chen, Y.-M.; Jiang, G.-Y.; Wang, X.-S. Imaging Sci. Photochem. 2016, 34, 297 (in Chinese). (陈雨濛, 姜国玉, 王雪松, 影像科学 与光化学, 2016, 34, 297.) 